\title{
SARS-COV-2 AS A REAL THREAT FOR HEALTHCARE WORKERS
}

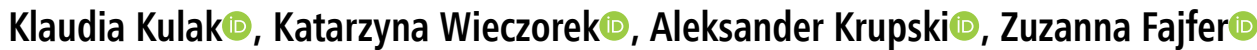

Student's Journal Club, Lazarski University, Warsaw, Poland

KEY WORDS: SARS-CoV-2; COVID-19, coronavirus, pandemic, healthcare worker, infection

Disaster Emerg Med J 2020; 5(2)

SARS-CoV-2 belongs to the Coronaviridae family, and it was probably initially transmitted from wild animals to humans [1]. Since the outbreak of the COVID-19 epidemic in December 2019 in Wuhan, China, the whole world is fighting an ever-growing pandemic, which becomes a global threat. The number of confirmed cases constantly increases and amounts to almost 1500 000, however, the number of infected people is increasing continuously, although at present the number of daily COVID-19 deaths is decreasing in some European countries, including Spain and Italy. With droplet transmission, virus released in the respiratory secretions when a person with infection coughs, sneezes or talks can infect another person if it makes direct contact with the mucous membranes $\left[{ }^{2}\right]$. The available research results show that the virus is a single-stranded RNA virus that belongs to the genus Beta-coronavirus, and in its sequence uses the receptor for convertase-2-angiotensin (ACE-2). This enzyme serves as the entry point into cells for SARSCoV-2 and may result in increased expression of proteins that cause damage to the lung alveolar system [3]. Based on analyzed cases, COVID-19 causes many symptoms including fever, dry cough, but more serious problem is bronchitis, pneumonia and ARDS. It was observed that younger patient can show severe disease symptoms, which is caused by non-educated immune system [4]. Elderly people and people with pre-existing medical conditions like hypertension, diabetes or cancer are more likely to become infected with a higher risk of severe COVID-19 and virus-related death [5]. The World Health Organization (WHO) published guidelines on how to avoid SARS-CoV-2 infection. Observing the rules of hygiene, reducing contact with other people the spread of the virus can be reduced. This is especially important because there are currently no medications or vaccines that can help avoid infection or cure its effects. The biggest problem is that we do not have enough knowledge about SARSCoV-2. It is a new pathogen that is highly transmittable and should be seen as a real threat. We should not refer to other diseases caused by other viruses but build knowledge based on constantly collected data. The most common clinical features at the onset of illness were: fever (87.9\%), dry cough $(67.7 \%)$, fatigue $(38.1 \%)$, sputum production (33.4\%), shortness of breath (18.6\%) and sore throat (13.9\%). Signs and symptoms are developed about 5-6 days after infection [6]. This is a huge threat to healthcare professionals. This means that infected patients with non-specific symptoms can easily infect during physical examination. Healthcare workers are in constant contact with them and after infection, they spread the virus to other co-workers before they develop symptoms. This is evidenced by the fact that $3.5 \%$ of infected people are healthcare workers [7]. In a case series of 138 patients treated in a Wuhan hospital, 40 patients (29\% of cases) were HCWs (31 (77.5\%) worked on general wards, $7(17.5 \%)$ in the emergency department, and $2(5 \%)$ in the intensive care unit) $)^{2}$. What is worst, they can infect other sick patients in hospital who are the most vulnerable group that had a case fatality rate of $10.5 \%$ for cardiovascular disease, $7.3 \%$ for diabetes, $6.3 \%$ for chronic respiratory disease, $6.0 \%$ for hypertension and $5.6 \%$ for cancer 
$[3,8]$. This means that we can expect an increase in the mortality of patients whose lives could be saved before the pandemic. Acute respiratory distress syndrome (ARDS) is a major complication. Common complications of COVID-19-related ARDS include acute kidney injury (AKI), elevated liver enzymes, and cardiac injury including cardiomyopathy, pericarditis, pericardial effusion, arrhythmia, and sudden cardiac death [8]. Protection against this virus as well as against any other infectious disease consists primarily in preventive measures. Maintaining hygiene and maintaining adequate distance from the patient. This includes maintaining a minimum distance of $1.5 \mathrm{~m}$ (however, this distance should probably be increased), frequent hand washing minimum $30 \mathrm{~s}$, disinfecting hands, not touching the face with hands, hygiene of the upper respiratory tract, wearing a mask with FFP2 filter, using PPE, disinfecting things and rooms [9].

In many countries, healthcare workers are particularly exposed to SARS-CoV-2 and account for a significant proportion of the infected population. However, the experience of the Chinese and Italian hospitals shows that infections of healthcare workers can be significantly reduced by strictly following the recommendations for the use of personal protective equipment and proper workplace management, including the limitation of working time to a maximum of 6 hours. Of course, testing for SARSCoV-2 and the availability of personal protective equipment and disinfectants are essential.

Conflict of interest: We have no conflict of interest.

\section{REFERENCES:}

1. Cui J, Li F, Shi ZL. Origin and evolution of pathogenic coronaviruses. Nat Rev Microbiol. 2019; 17(3): 181-192, doi: 10.1038/s41579-0180118-9, indexed in Pubmed: 30531947.

2. Smereka J, Szarpak L, Filipiak K. Modern medicine in COVID-19 era. Disaster and Emergency Medicine Journal. 2020, doi: 10.5603/demj. a2020.0012.

3. Gheblawi M, Wang K, Viveiros $A$, et al. Angiotensin Converting Enzyme 2: SARS-CoV-2 Receptor and Regulator of the Renin-Angiotensin System. Circ Res. 2020 [Epub ahead of print], doi: 10.1161/ CIRCRESAHA.120.317015, indexed in Pubmed: 32264791.

4. Zhang J, Litvinova $M$, Wang W, et al. Evolving epidemiology and transmission dynamics of coronavirus disease 2019 outside Hubei province, China: a descriptive and modelling study. The Lancet Infectious Diseases. 2020, doi: 10.1016/s1473-3099(20)30230-9.

5. Onder G, Rezza G, Brusaferro S. Case-Fatality Rate and Characteristics of Patients Dying in Relation to COVID-19 in Italy. JAMA. 2020 [Epub ahead of print], doi: 10.1001/jama.2020.4683, indexed in Pubmed: 32203977.

6. Ruetzler K, Szarpak L, Filipiak K, et al. The COVID-19 pandemic - a view of the current state of the problem. Disaster and Emergency Medicine Journal. 2020, doi: 10.5603/demj.a2020.0015.

7. Wang D, Hu Bo, Hu C, et al. Clinical Characteristics of 138 Hospitalized Patients With 2019 Novel Coronavirus-Infected Pneumonia in Wuhan, China. JAMA. 2020 [Epub ahead of print], doi: 10.1001/ jama.2020.1585, indexed in Pubmed: 32031570.

8. Inciardi RM, Lupi L, Zaccone G, et al. Cardiac Involvement in a Patient With Coronavirus Disease 2019 (COVID-19). JAMA Cardiol. 2020 [Epub ahead of print], doi: 10.1001/jamacardio.2020.1096, indexed in Pubmed: 32219357.

9. Smereka J, Szarpak L. COVID 19 a challenge for emergency medicine and every health care professional. Am J Emerg Med. 2020 [Epub ahead of print], doi: 10.1016/j.ajem.2020.03.038, indexed in Pubmed: 32241630 . 